\title{
Maculopathy, Fundus Changes and Anterior Lenticonus in Alport Syndrome
}

\author{
Mirko Ratkovic, ${ }^{1}$ (i) Ajla Pidro, ${ }^{2}$ (i) Aida Pidro ${ }^{3}$
}

${ }^{1}$ Department of Ophthalmology, University Eye Clinic Svjetlost Zagreb, Croatia

2Department of Ophthalmology, Eye Clinic “Dr. Ismail”, Sarajevo, Bosnia and Herzegovina

${ }^{3}$ Department of Ophthalmology at General Hospital "Prim. Dr. Abdulah Nakas", Sarajevo, Bosnia and Herzegovina

\begin{abstract}
Alport syndrome is a rare basement membrane disorder that may include ocular manifestations: dot-and-fleck retinopathy, anterior lenticonus, posterior polymorphous corneal dystrophy, or temporal macular thinning. It is primarily an X-linked inheritance condition (85\%). This case report describes a $5 \mathrm{I}$-year-old male patient with Alport syndrome who was diagnosed due to ocular manifestations that were subsequently linked with a history of renal failure and bilateral sensorineural hearing loss. The diagnostic tools used were biomicroscopy, ultrasound, corneal topography, endothelial microscope analysis, macula optical coherence tomography, and fundus photography. Clear lens extraction was performed and improved his visual acuity. Further genetic analysis revealed a mutation in the COL4A5 gene on the $X$ chromosome. Ocular manifestations can help determine the right diagnosis and help in multisystemic disease assessment. In cases of Alport syndrome, a nephrologist should be informed about the potential development of a specific antiglomerular basement membrane antibody that may lead to graft rejection. The patient's close relatives should also be examined.
\end{abstract}

Keywords: Alport syndrome, dot-and-fleck retinopathy, lenticonus

\section{Introduction}

Alport syndrome is a hereditary disorder resulting from mutations in the COL4A5 (X-linked) or COL4A3 and COL4A4 (autosomal recessive) collagen genes, which can lead to the absence of collagen IV in basement membranes in the kidney glomeruli, cochlea, or the lens, and cause hematuria, renal failure, sensorineural hearing loss, and ocular abnormalities in the cornea, lens, or retina (I). Most cases ( $85 \%$ ) are classified as an X-linked inheritance (XLAS), while an autosomal recessive (ARAS) classification accounts for 10\%, and $5 \%$ are categorized as autosomal dominant Alport's syndrome (ADAS) (I). This case report describes characteristic ocular manifestations that were instrumental in making a diagnosis of Alport syndrome.

\section{Case Report}

A $5 \mathrm{I}$-year-old male patient presented with progressive high myopia of the left eye and gradual decreased left eye visual acuity. The right eye was amaurotic due to a prior trauma. A complete ophthalmological exam was performed, including slit-lamp examination, ultrasound, corneal topography, endothelial microscope examination, optical coherence tomography (OCT), and fundus photography. The results for the left eye were a best corrected visual acuity (BCVA) of 0.4 $\left(-14.0 /-0.5 / 90^{\circ}\right)$, an unremarkable ultrasound with an axial

How to cite this article: Ratkovic M, Pidro A, Pidro A. Maculopathy, Fundus Changes and Anterior Lenticonus in Alport Syndrome. Beyoglu Eye J 202I; 6(I): 66-69.

Address for correspondence: Aida Pidro, MD. Oftalmoloji Bolumu, Goz Klinigi "Dr. Ismail ", Saraybosna, Bosna Hersek Phone: +38733205090 E-mail: aida.pidro@gmail.com

Submitted Date: December 02, 2020 Accepted Date: January 12, 2021 Available Online Date: February 11, 2021

${ }^{\circ}$ Copyright 2021 by Beyoglu Eye Training and Research Hospital - Available online at www.beyoglueye.com OPEN ACCESS This work is licensed under a Creative Commons Attribution-NonCommercial 4.0 International License. 
length of $22.99 \mathrm{~mm}$ and an anterior chamber depth of 2.99 $\mathrm{mm}$ (Fig. Ia), unremarkable biometry (Fig. Ib) findings, anterior lenticonus visible with a Pentacam camera system (Oculus Inc., Menlo Park, CA, USA) (Fig. Ic), oil droplet sign, and anterior lenticonus seen in a slit lamp examination (Fig. 2a, b), and distorted and blurred fundus images with discernable but unclear dots and flecks (Fig. 3a-c).

A full patient history revealed kidney failure at the age of 25 and eventual kidney transplantation without specific information of a precise diagnosis or the cause of the renal failure. An ear, nose, and throat (ENT) examination revealed bilateral hearing loss as well. Based on the combination of these symptoms, Alport syndrome was suspected and later confirmed with genetic analysis that confirmed the presence
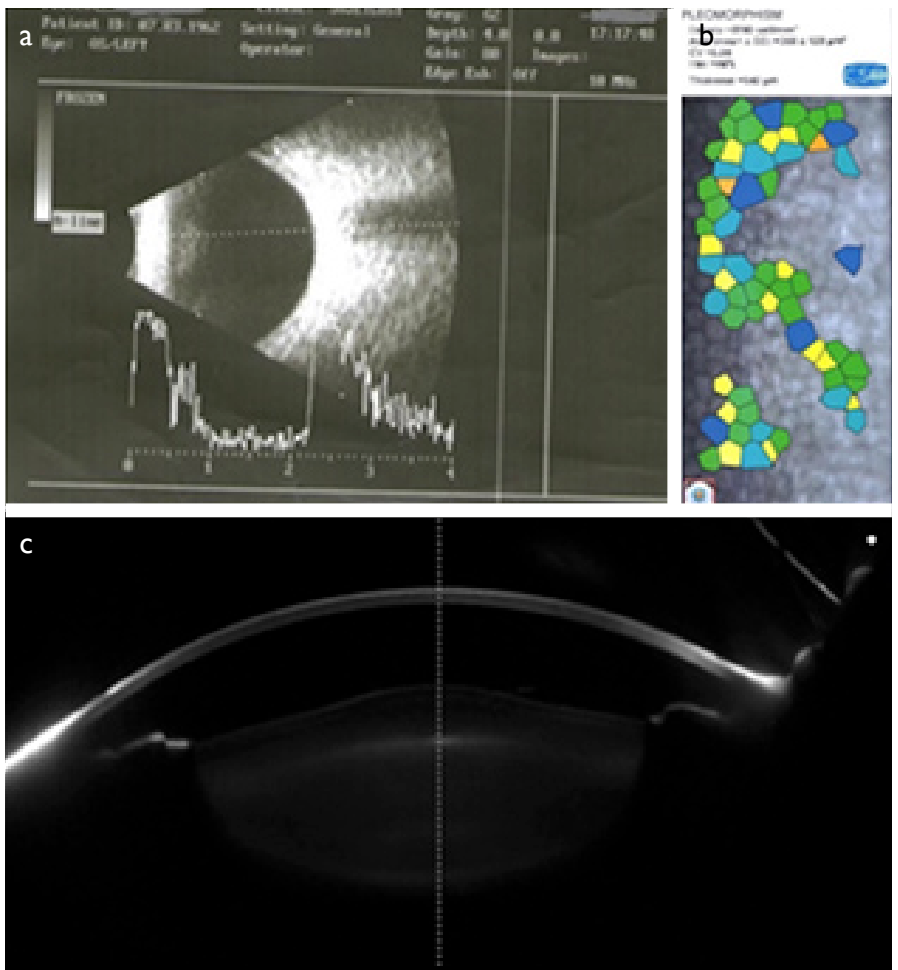

Figure I. (a) Left eye ultrasound (axial length: $22.99 \mathrm{~mm}$; flat keratotomy: $43.01 \mathrm{D} / 7.72 \mathrm{~mm} @ 2^{\circ}$; steep keratotomy: $45.48 \mathrm{D} / 7.30 \mathrm{~mm}$ @ 92 ; right/spherical equivalent: $7.51 \mathrm{~mm} / 44.24 \mathrm{D}$; cylinder: $2.47 \mathrm{D}$ @ $92^{\circ}$; anterior chamber depth: $2.99 \mathrm{~mm}$ ), (b) unremarkable left eye biometry scan, (c) camera image showing left anterior lenticonus.
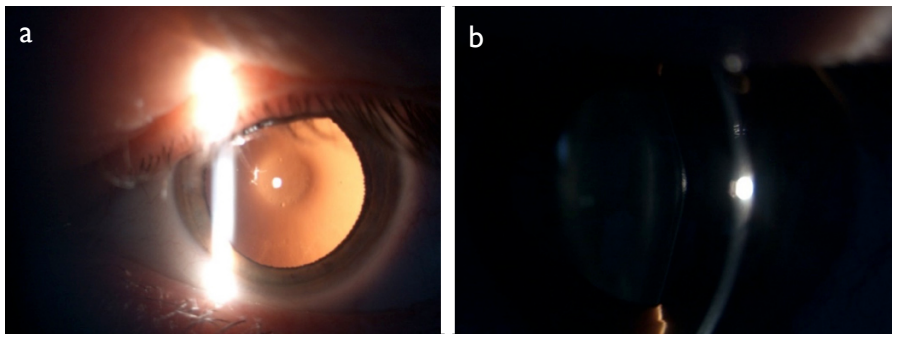

Figure 2. Left eye slit lamp examination revealing (a) oil droplet sign, and (b) anterior lenticonus. of a mutation in the COL4A5 gene of the $X$ chromosome. The patient was referred to a nephrologist.

Blurred retinal images and decreased visual acuity caused by anterior lenticonus were indications for clear lens extraction with intraocular lens implantation (Fig. 4a, b). The postsurgical BVCA was 0.9 with a $+2.75 \mathrm{D}$ presbyopic addition. The patient no longer had a subjective visual complaint. Clear lens extraction was beneficial for clearing the media and allowing for macular OCT and clear fundus photography to be performed. Left eye macular OCT showed temporal macular thining (Fig. 5a) and fundus photography displayed dot-and-flek retinopathy (Fig. 5b-d).

\section{Discussion}

Alport syndrome is an inherited disease affecting an estimated I in 10.000 individuals (2). It typically includes a combination of progressive hereditary renal failure, sensorineural and usually bilateral hearing loss ( $80 \%)$, and ocular abnormalities (found in approximately $40 \%$ ) (3). Collagen IV is an important basement membrane-protein, found in the glomerulus, cochlea, Descemet's and Bowman's membranes of the cornea, capsule of the lens, and the inner limiting and Bruch's membrane of the retina (4).

The renal system usually displays the first symptoms at an early age, starting with hematuria and progressing with proteinuria followed by high blood pressure even in the teenage years. Kidney failure can appear in early adulthood or may be delayed until the age of 40 to 50 years (5). In our case, the patient did not report any major symptoms during childhood, but in early adulthood, he developed end-stage renal disease with no clear cause. This is usually the case in a male with XLAS, whereas females with XLAS usually do not develop kidney failure (5). The usual diagnostic procedure for Alport syndrome would be a kidney biopsy, but since this patient had already had a kidney transplant, this diagnostic technique could not be used.

Bilateral sensorineural hearing loss usually appears by the age of 10 , often parallel to the appearance of renal symptoms (5). Our patient had clinically apparent hearing loss, but he attributed this to the prior trauma when he lost vision in the other eye. Hearing loss in Alport syndrome is more frequent in males than females. These symptoms appear due to cochlear lesions, similar to those in the glomerular basement membrane (6).

The cornea is affected in $<10 \%$ of patients (7). It most often presents in the form of erosions or posterior polymorphous dystrophy from an abnormal Bowman's membrane and Descemet's membrane, respectively, in the subendothelium (I). Erosion could lead to the recurrent episodes of ocular pain, photophobia, or blurred vision lasting 2 to 5 days (8). Posterior polymorphous corneal dystrophy occurs less 


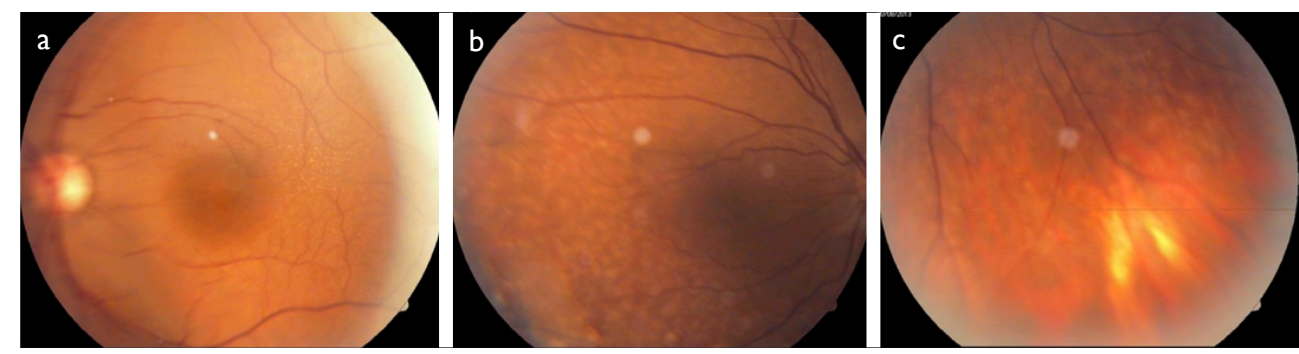

Figure 3. (a-c) Distorted and blurred fundus images with dots and flecks.
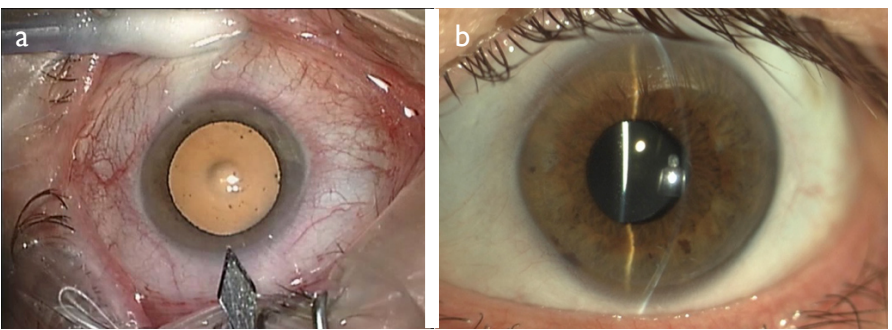

Figure 4. (a) Before surgery, and (b) after surgery.

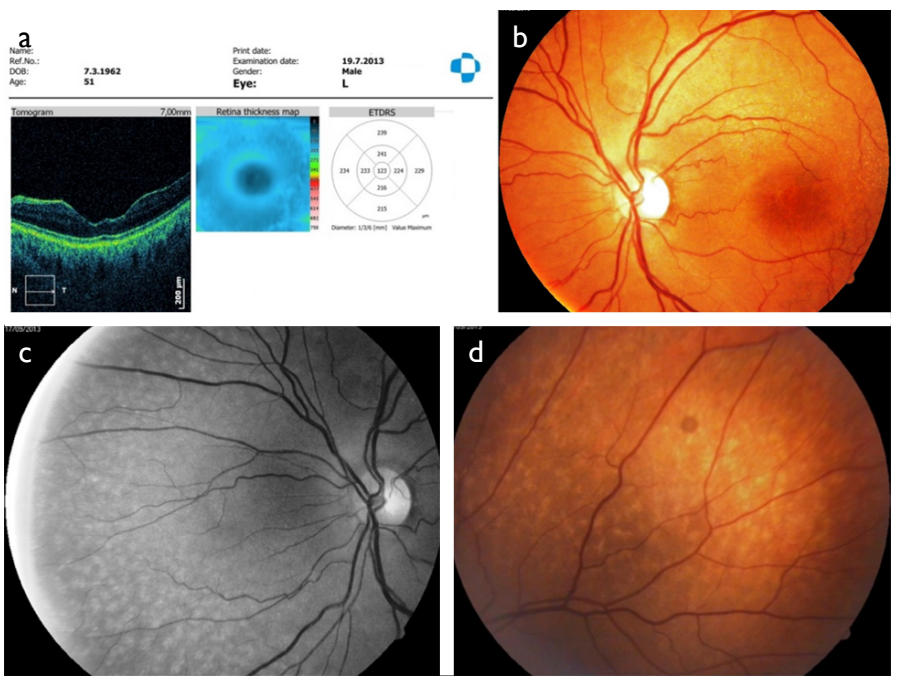

Figure 5. (a) Left eye macular optical coherence tomography image revealing macular thinning, and (b-d) left eye fundus photography displaying dot-and-fleck retinopathy.

often than erosions, and includes symptoms of photophobia, epiphora, or grittiness (7). Our patient did not present with any of these corneal signs.

The lens can be affected in a form of cataract and anterior lenticonus. Lenticonus, abnormality in the shape of the lens, is a pathognomonic feature of Alport syndrome and is a result of a conical anterior lens protrusion through the thinnest capsular area (9). In XLAS cases, it affects males more than females, and is usually associated with existing renal failure ( $\mathrm{I}$ ). Cataract can develop as a result of a process of healing of spontaneous capsular ruptures, which appear due to the absence of mentioned genes (I). A pathognomonic indicator of lenticonus is an oil droplet sign seen on a slit-lamp examination. The abnormal lens shape reduces image focus capacity and further decreases visual acuity, leading to the necessity for phacoemulsification with intraocular lens implantation (10), as in this case. Myopic shift due to anterior lenticonus leads to blurry vision and an inability to perform a good fundus examination. In this case, phacoemulsification with IOL implantation (Sensar, AR40e +22.0 D; Johnson and Johnson, Inc., New Brunswick, NJ, USA) was performed.

The retina is most commonly affected in the form of dotand-fleck retinopathy, which is a sign of an abnormal retinal pigment, in a central or perimacular area or the periphery. It usually does not affect visual acuity or require treatment, as in our case. Peripheral lesions are more common and more associated with early signs of renal failure (I). Other manifestations include temporal macular thinning, which can lead to a weakened foveolar reflex, foveal pigment disruption, vitelliform maculopathy, or even macular holes (I). In our case, temporal thinning was confirmed with macular OCT scans. Though less sensitive, OCT is more objective than peripheral retinopathy (II). Macular holes, either lamellar or giant, are less common and appear due to collagen IV abnormalities in the internal limiting membrane (ILM) or Bruch's membrane (12). In this case OCT revealed slight thickening of the ILM.

Most ocular features do not affect vision, with the exception of malformations of the lens, but are diagnostically and prognostically useful as they can help to distinguish the inheritance type. Inherited renal disease is commonly associated with hearing loss, which makes ocular features more specific for Alport syndrome diagnostics (I). Some studies have shown that ocular malformations are usually present in the late stage of this syndrome and that most patients already have renal failure and bilateral hearing loss (5), which can also indicate a poorer prognosis for these patients.

Most ocular symptoms can be easily overlooked because they can be very subtle and cause no visual acuity defects. It is, therefore, very important to do a detailed ophthalmological examination, including fundus photography and OCT macular scans, and to obtain a detailed history about renal and hearing symptoms and refer the patient to a nephrologist promptly. If a child has been diagnosed with Alport syndrome, even with no ophthalmological manifestations present, the mother should also be ophthalmologically examined. 
Male sex combined with ophthalmological finding of dotand-flack retinopathy, temporal macular thinning, and anterior lenticonus combined with a medical history of renal failure, renal transplantation, and sensorineural hearing loss led to a clinical diagnosis of Alport syndrome with the classic triad: hemorrhagic nephritis, sensorineural hearing loss, and characteristic ocular findings. Early diagnosis is important in order to provide the appropriate multidisciplinary treatment by a nephrologist, an ENT specialist, and an ophthalmologist. Early intervention can provide a better renal, hearing, and vision prognosis and therefore, better quality of life.

\section{Disclosures}

Informed consent: Written informed consent was obtained from the patient for the publication of the case report and the accompanying images.

Peer-review: Externally peer-reviewed.

Conflict of Interest: None declared.

Authorship Contributions: Involved in design and conduct of the study (MR, AP, AP); preparation and review of the study (MR, AP, AP); data collection (MR,AP,AP).

\section{References}

I. Savige J., Sheth S., Leys A. Ocular features in Alport's syndrome: pathogenesis and clinical significance. Clin J Am Soc Nephrol 2015;10:703-9. [CrossRef]

2. Temme J, Kramer A, Jager KJ, Lange K, Peters F, Müller GA, et al. Outcomes of male patients with Alport syndrome undergoing renal replacement therapy. Clin J Am Soc Nephrol 2012;7:1969-76. [CrossRef]

3. Raja AM, Janti SS, Matheen A, Chendilnathan C. Ocular manifestation of the Alport syndrome: A case report. Muller J Med
Sci Res 2015;6:89-9I. [CrossRef]

4. Kabosova A, Azar DT, Bannikov GA, Campbell KP, Durbeej M, Ghohestani RF, et al. Compositional differences between infant and adult human corneal basement membranes. Invest Ophthalmol Vis Sci 2007;48:4989-99. [CrossRef]

5. Xu JM, Zhang SS, Zhang Q, Zhou YM, Zhu CH, Ge J, Wang L. Ocular manifestations of Alport syndrome. Int J Ophthalmol 2010;3:149-51.

6. Kashtam CE, Michael AF. Alport syndrome: from bedside to genome to bedside. Am J Kidney Dis 1993;22:627-40. [CrossRef]

7. Rhys C, Snyers B, Pirson Y: Recurrent corneal erosion associ- ated with Alport's syndrome. Rapid communication. Kidney Int 1997;52:208-1 I. [CrossRef]

8. Burke JP, Clearkin LG, Talbot JF. Recurrent corneal epithelial erosions in Alport's syndrome. Acta Ophthalmol (Copenh) 1991;69:555-7. [CrossRef]

9. Ohkubo $\mathrm{S}$, Takeda $\mathrm{H}$, Higashide T, Ito M. Immunohistochemical and molecular genetic evidence for type IV collagen alpha5 chain abnormality in the anterior lenticonus associated with Alport syndrome. Arch Ophthalmol 2003;121:846-50. [CrossRef]

10. Liu YB, Tan SJ, Sun ZY, Li X, Huang BY, Hu QM. Clear lens phacoemulsification with continuous curvilinear capsulorhexis and foldable intraocular lens implantation for the treatment of a patient with bilateral anterior lenticonus due to Alport syndrome. J Int Med Res 2008;36: 1440-4. [CrossRef]

II. Ahmed F, Kamae KK, Jones DJ, Deangelis MM, Hageman GS, Gregory MC, Bernstein PS. Temporal macular thinning associated with X-linked Alport syndrome. JAMA Ophthalmol 2013;131:777-82. [CrossRef]

12. Rahman W, Banerjee S. Giant macular hole in Alport syndrome. Can J Ophthalmol 2007;42:3।4-5. [CrossRef] 